\title{
Estaquia herbácea de porta-enxertos de pessegueiro no final do verão
}

\section{Herbaceous cutting propagation of peach rootstocks in late summer}

\author{
Newton Alex Mayer ${ }^{1 *}$; Luciano Picolotto ${ }^{2}$; Pedro Vieira Bastos ${ }^{3}$; \\ Bernardo Ueno $^{1}$; Luis Eduardo Corrêa Antunes ${ }^{1}$
}

\begin{abstract}
Resumo
Diante da necessidade de ampliar o período de realização da estaquia herbácea de porta-enxertos de pessegueiro, visando otimização da infra-estrutura instalada nos viveiros, idealizou-se o presente trabalho, que teve por objetivo estudar sua viabilidade técnica em quatro cultivares, no final do verão. Utilizou-se da extremidade distal (último fluxo de crescimento) dos ramos de pessegueiros 'Tsukuba-1', 'Tsukuba-2', 'Tsukuba-3' e 'Okinawa', testando-se também as doses 0; 3.000 e 6.000 mg.L-1 de ácido indolbutírico, em imersão rápida. Transcorridos 60 dias após a estaquia, foram avaliadas variáveis relativas ao enraizamento e à qualidade das raízes. Conclui-se que o uso de ramos herbáceos, oriundos do ultimo fluxo de crescimento, para a estaquia em março, proporciona resultados satisfatórios para os porta-exertos 'Okinawa' e 'Tsukuba 1'. Os três porta-enxertos da série 'Tsukuba' testados apresentam diferenças nas porcentagens de enraizamento, de estacas aptas e inaptas ao transplantio, no comprimento das raízes e na porcentagem de mortalidade. Recomenda-se o ácido indolbutírico a $6.000 \mathrm{mg}$. $\mathrm{L}^{-1}$ para o tratamento das estacas herbáceas dos porta-enxertos testados, para estaquia em março.
\end{abstract}

Palavras-chave: Prunus persica, propagação vegetativa, clonagem

\begin{abstract}
Due to the necessity of extending the season to root peach herbaceous cuttings and optimize plant nurseries facilities, the present research had as goal to study technical viability of late summer rooting on four peach rootstocks. Distal portion (last growth) was used of branches of 'Tsukuba-1', 'Tsukuba-2', 'Tsukuba-3' and 'Okinawa' peach rootstocks and tested with different indolbutyric acid (IBA) concentrations $\left(0 ; 3,000\right.$; and $\left.6,000 \mathrm{mg} . \mathrm{L}^{-1}\right)$ by fast immersion. Sixty days after the treatments, rooting and root quality were measured. We conclude that using herbaceous branches from the last growth on March provides satisfactory results for 'Tsukuba-1' and 'Okinawa' rootstocks. The three Tsukuba rootstocks showed differences in rooting percentage, percentage of suitable and unsuitable cuttings for planting, root length and mortality percentage. IBA at $6,000 \mathrm{~m} \cdot \mathrm{L}^{-1}$ on March can be recommended for herbaceous cutting treatment of the studied peach rootstocks.
\end{abstract}

Key words: Prunus persica, vegetative propagation, cloning

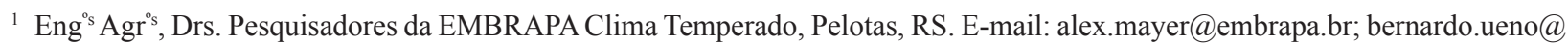
embrapa.br; luis.antunes@embrapa.br

${ }^{2}$ Eng $^{\circ} \mathrm{Agr}^{\circ}$, Dr. Bolsista PNPD/CAPES na EMBRAPA Clima Temperado, Pelotas, RS. E-mail: picolotto@gmail.com

${ }_{3}^{3}$ Discente do Curso de Graduação em Ecologia, Universidade Católica de Pelotas, UCPel, bolsista da Embrapa Clima Temperado, Pelotas, RS. E-mail: peuvieirab@gmail.com

* Autor para correspondência 


\section{Introdução}

A produção, a produtividade e a qualidade das frutas estão intimamente relacionadas à qualidade das mudas. Conforme o estabelecido pela Instrução Normativa $\mathrm{N}^{\circ} 24$, de 16 de dezembro de 2005, publicada no DOU - Seção 1, de 20 de dezembro de 2005 (BRASIL, 2005), e pela norma estadual gaúcha (COMISSÃO, 1998), as mudas enxertadas de pessegueiro devem ter identidade genética conhecida, tanto da cultivar copa como do portaenxerto. No entanto, no tradicional sistema de produção de mudas de pessegueiro no Sul do Brasil, são utilizadas misturas de caroços de diversas cultivares-copa oriundas das indústrias de conservas para a formação dos porta-enxertos. Desta forma, têm-se a garantia da fidelidade genética apenas da cultivar-copa (devido à enxertia), mas não do portaenxerto (PEREIRA; MAYER, 2005).

Alternativamente a esse modo de obtenção de caroços, alguns viveiristas têm procurado formar matrizeiros próprios com cultivares de porta-enxerto, a exemplo das cultivares Okinawa, Flordaguard, Nemaguard, Rigitano e dos porta-enxertos da Série 'Tsukuba'. Entretanto, nesses matrizeiros, pode ocorrer polinização cruzada entre as cultivares de floração coincidente, o que produzirá sementes híbridas e com identidade genética diferente da planta mãe. Segundo Miller, Parfitt e Weinbaum (1989), as taxas de polinização cruzada são bastante variáveis em pessegueiro, podendo chegar a 33 $\%$, dependendo do ano. A polinização cruzada é influenciada principalmente pelo comportamento dos insetos polinizadores (abelhas), além de fatores relativos ao ambiente, como a densidade de flores, as fontes alternativas de pólen, o tamanho e a forma do pomar. Desta forma, os autores alertam que não se pode assumir que houve auto-polinização e que seus descendentes serão homogêneos, em plantas matrizes de pessegueiro de polinização aberta, quando estas encontram-se próximas a outros genótipos.

Outro inconveniente da propagação por sementes, em algumas das cultivares que possuem baixa exigência de frio, é a coincidência da floração e início da frutificação com as geadas, o que tem provocado, em alguns anos, reduções e até ausência do pegamento de frutos na Região de Pelotas-RS, o que tem comprometido a disponibilidade de sementes para a produção de porta-enxertos.

Segundo Yoshida (1995), o uso de sementes para a propagação de porta-enxerto, mesmo usando cultivares selecionadas para esse fim, pode levar à ocorrência de variabilidade para algumas características da cultivar copa, além de desuniformidade de vigor (ANCU et al., 2009). Para manter a uniformidade no desenvolvimento do pessegueiro, é importante o uso de porta-enxertos clonais, obtidos por propagação vegetativa. Nesse contexto, é necessário que a pesquisa brasileira viabilize um método eficiente, prático e econômico para a propagação vegetativa de porta-enxertos do gênero Prunus spp. e que possa ser de fácil adoção pelos viveiristas, o que dispensaria a produção de sementes e/ou a dependência de fornecedores de outros estados brasileiros.

A pesquisa na área de propagação vegetativa de porta-enxertos de Prunus spp. vem obtendo resultados interessantes com o uso de estacas herbáceas, sob câmara de nebulização intermitente (NACHTIGAL, 1999; MAYER; PEREIRA; NACHTIGAL， 2001; MINDÊLO NETO; BALBINOT JÚNIOR; HIRANO, 2004). Entretanto, devido às condições climáticas do inverno na região Sul do Brasil, este método normalmente tem sido realizado entre novembro e fevereiro, o que tem subutilizado a estrutura de propagação durante o ano e também tem desencorajado os viveiristas a realizar investimentos nessa tecnologia. Nesse sentido, informações técnicas são necessárias visando ampliar o período de realização da estaquia herbácea, com o uso de algumas cultivares de portaenxerto com potencial de uso na Região Sul do Brasil, como a 'Okinawa' e as da Série 'Tsukuba' (DE ROSSI et al., 2004; ROCHA et al., 2007). 
As cultivares de porta-enxerto de pessegueiro da série 'Tsukuba' (1 ao 10) foram desenvolvidos pela Estação Experimental de Fruticultura do Ministério de Agricultura do Japão, em Tsukuba. As cultivares 'Tsukuba 1' a '6' são de folha vermelha e as 'Tsukuba 7' a '10' são de folha verde. Todas essas cultivares da série 'Tsukuba' de folha vermelha apresentam resistência para o nematóide das galhas (Meloidogyne incognita, M. javanica e M. mali), sendo que o caráter genético para folha vermelha e resistência ao nematóide das galhas é dominante. Para incorporar a cor vermelha nas folhas nos porta-enxertos 'Tsukuba 1' a '6', foi utilizado o pessegueiro 'Akame', nos cruzamentos e, para a obtenção da resistência aos nematóides das galhas, foram utilizados 'Okinawa' e 'Juseito' (YOSHIDA, 1995). O porta-enxerto 'Okinawa' foi testado por Sharpe (1957) na Estação Experimental da Flórida, a partir de sementes obtidas das ilhas de Ryukyu, em Okinawa, Japão, sendo detectada resistência a Meloidogyne javanica, M. incognita e M. acrita. No Brasil, o porta-enxerto 'Okinawa' foi introduzido pelo Instituto Agronômico de Campinas (IAC), em 1969, por meio de intercâmbio de material genético com a Universidade da Flórida, e continua sendo o porta-enxerto mais utilizado no Estado de São Paulo (PEREIRA; MAYER, 2005).

O enraizamento de estacas de ramos é afetado por fatores externos, como a cultivar, a concentração de ácido indolbutírico, a data de coleta dos ramos, o tempo transcorrido da coleta dos ramos até a estaquia, a idade da planta matriz e também pelo comprimento e o diâmetro das estacas (TSIPOURIDIS; THOMIDIS; MICHAILIDES, 2005). Estes fatores possivelmente relacionamse com fatores endógenos, como os conteúdos de açúcares, sacarose, amido, ácido indolacético, ácido abscísico, sólidos solúveis totais e elementos minerais, os quais são variáveis ao longo do ano (TSIPOURIDIS; THOMIDIS; BLADENOPOULOU, 2006a; TSIPOURIDIS; THOMIDIS; BLADENOPOULOU, 2006b). Entre os fatores endógenos, as auxinas desempenham importante papel no enraizamento adventício, mas também podem ser fornecidas de forma exógena, com o uso de formulações sintetizadas.

Em porta-enxertos do gênero Prunus spp., é bem conhecida a necessidade da aplicação de ácido indolbutírico em estacas herbáceas e semilenhosas, entretanto, a concentração ótima é variável e dependente dos demais fatores externos, bem como da condição fisiológica da planta-matriz (NACHTIGAL, 1999; MURAIetal., 1999; MAYER; PEREIRA; NACHTIGAL, 2001; TOFANELLI; ONO; RODRIGUES, 2003; AGUIAR et al., 2005; MINDÊLLO NETO; BALBINOT JÚNIOR; HIRANO, 2004; TWORKOSKI; TAKEDA, 2007; CANLI; BOZKURT, 2009; CARDOSO et al., 2011).

Nachtigal (1999), testando concentrações de ácido indolbutírico ( 0 e $2.000 \mathrm{mg} \cdot \mathrm{L}^{-1}$ ) em estacas herbáceas de 'Okinawa', obteve 86,96 e 99,81\% de enraizamento, respectivamente. Tofanelli, Ono e Rodrigues (2003) verificaram que, para estacas herbáceas de cultivares de pessegueiro, a imersão rápida por 5 segundos, utilizando-se soluções mais concentradas de ácido indolbutírico (1.250; 2.500 ou $3.750 \mathrm{mg} . \mathrm{L}^{-1}$ ) são mais efetivas ao enraizamento do que a imersão lenta por 24 horas, utilizando-se soluções mais diluídas (100; 200 ou 300 mg.L.-1) do fitorregulador. Nas condições climáticas do outono/ inverno em Londrina-PR, é possível a realização da estaquia semi-lenhosa de 'Okinawa' sob câmara de nebulização, com resultados bastante variáveis, podendo chegar a $68 \%$ de enraizamento (AGUIAR et al., 2005; CARDOSO et al., 2011).

O presente trabalho teve por objetivo estudar a viabilidade técnica do uso da estaquia herbácea no final do verão, em quatro cultivares de portaenxerto para pessegueiro, com potencial de uso na região Sul do Brasil.

\section{Material e Métodos}

Plantas matrizes com 19 meses de idade das cultivares de porta-enxerto Okinawa, Tsukuba-1, Tsukuba-2 e Tsukuba-3 [Prunus persica (L.) 
Batsch], pertencentes à "Coleção Porta-enxerto de Prunus" da Embrapa Clima Temperado, foram utilizadas como fonte doadora de material propagativo. A referida coleção localiza-se no Município de Pelotas-RS, Brasil, latitude de $31^{\circ} 40^{\prime}$ $42,7^{\prime}$ S, longitude $52^{\circ} 27^{\prime} 3,8^{\prime}$ 'O e com altitude de aproximadamente $60 \mathrm{~m}$.

No inverno de 2009, realizou-se a poda de formação nas plantas matrizes, em forma de taça, à semelhança da preconizada para a produção de frutos. Em 15 de março de 2010, foram colhidos ramos herbáceos dessas plantas, com aproximadamente 30 a $40 \mathrm{~cm}$ de comprimento, correspondentes ao último fluxo de crescimento. Esse último fluxo de crescimento apresentava consistência tipicamente herbácea e, no caso das cultivares da série 'Tsukuba', também a coloração vermelha típica nos ramos e nas folhas (faces abaxial e adaxial), o que permitiu fácil diferenciação em relação à porção anterior do mesmo ramo. Imediatamente após a coleta e identificação, os ramos foram levados à câmara de nebulização intermitente, para evitar a desidratação das folhas durante o preparo das estacas. As estacas foram preparadas com 12 $\mathrm{cm}$ de comprimento, permanecendo com 3 a 6 folhas inteiras (NACHTIGAL, 1999; MAYER; PEREIRA; NACHTIGAL, 2001). Após o preparo, as estacas foram submetidas ao tratamento com ácido indolbutírico em solução liquida, por cinco segundos, com uma das seguintes doses: 0 mg. $\mathrm{L}^{-1}$, $3.000 \mathrm{mg} . \mathrm{L}^{-1}$ ou $6.000 \mathrm{mg} \cdot \mathrm{L}^{-1}$.

Caixas plásticas $(46 \times 30 \times 10 \mathrm{~cm})$, com as bases perfuradas (24 furos/caixa, com $11 \mathrm{~mm}$ de diâmetro), foram preenchidas com uma camada inferior de $2 \mathrm{~cm}$ de pedra britada $\mathrm{n}^{\circ} 2$ e, sobre esta, vermiculita de grânulos médios, até as bordas. As estacas foram acondicionadas nas caixas, contendo a vermiculita previamente umedecida, a uma profundidade de, aproximadamente, sete centímetros. As caixas foram mantidas sobre bancadas de ferro, com $1 \mathrm{~m}$ de altura, em estufa agrícola tipo arco (24 x $8 \mathrm{~m}$, com $3 \mathrm{~m}$ de pé direito) com teto de polietileno transparente e laterais com tela anti-insetos, sem controle de temperatura ou umidade relativa do ar. O experimento foi realizado sob sistema de nebulização intermitente, instalado no interior da estufa agrícola, com uma linha de nebulizadores dispostos sobre cada bancada, a $70 \mathrm{~cm}$ acima das caixas plásticas. O sistema de nebulização foi programado para ser acionado por 15 segundos, em intervalos de 2,5 minutos, o que permitiu a manutenção de umidade constante sobre a superfície das folhas.

$\mathrm{O}$ experimento foi instalado segundo delineamento inteiramente casualizado, fatorial $4 \mathrm{x}$ 3 , com três repetições de 25 estacas cada, totalizando 36 parcelas. Os fatores testados foram portaenxerto ('Tsukuba-1', 'Tsukuba-2', 'Tsukuba-3' e 'Okinawa') e doses de ácido indolbutírico (0 mg. $L^{-1}, 3.000$ mg. $L^{-1}$ e 6.000 mg. $\left.L^{-1}\right)$. Aos 60 dias após a estaquia, foram realizadas as avaliações das seguintes variáveis (expressas em porcentagem): estacas enraizadas, com calo, mortas e verdes (aquelas que não se enquadraram em nenhuma das classes anteriores). As estacas enraizadas foram classificadas visualmente em aptas e inaptas ao transplantio (expressando-as em porcentagem em relação ao total de estacas enraizadas), levando-se em conta a qualidade das raízes e sua distribuição ao redor da estaca. Avaliaram-se também o número de raízes por estaca e o comprimento das cinco maiores raízes de cada estaca. Os dados das variáveis expressas em porcentagem foram transformados para arc sen $\sqrt{x / 100} \mathrm{e}$, das demais variáveis, não foram transformados. Os dados foram submetidos à análise de variância pelo teste $\mathrm{F}$ e as médias comparadas pelo teste de Tukey a $5 \%$ de probabilidade.

\section{Resultados e Discussão}

Houve diferenças estatísticas significativas entre os porta-enxertos nas porcentagens de enraizamento, de estacas verdes, com calo e mortas (Tabela 1). Destacaram-se os porta-enxertos 'Okinawa' e 'Tsukuba-1', os quais apresentaram 
as maiores porcentagens de enraizamento $(57,33$ e $46,67 \%$, respectivamente) e as menores de mortalidade (4,0 e 17,78\%, respectivamente). Esses resultados revelam a possibilidade técnica de se utilizar o último fluxo de crescimento dos ramos das plantas matrizes para o preparo de estacas herbáceas, com a estaquia sendo realizada em meados do mês de março, até então considerada como época inadequada para a estaquia herbácea de pessegueiro no Rio Grande do Sul. Hartmann et al. (2002), consideram economicamente aceitáveis percentuais de enraizamento à partir de $50 \%$. Para estaquia semi-lenhosa de 'Okinawa' sob câmara de nebulização, realizada no mês de abril em LondrinaPR, Cardoso et al. (2011) classificaram como sucesso os percentuais de enraizamento obtidos entre 58 e $68 \%$. Salienta-se que no tradicional método de produção de porta-enxertos no Sul do Brasil, realizado com germinação de caroços de diversas cultivares-copa de pessegueiro, provenientes das indústrias de conservas, normalmente tem sido obtidas porcentagens de germinação inferiores a 40\% (MAYER; ANTUNES, 2010).

Tabela 1. Porcentagem de estacas enraizadas, de estacas verdes, de calo e de estacas mortas, em quatro cultivares de porta-enxertos para pessegueiro tratadas com diferentes doses de ácido indolbutírico. Embrapa Clima Temperado, Pelotas-RS, maio de 2010.

\begin{tabular}{|c|c|c|c|c|}
\hline $\begin{array}{l}\text { Porta- } \\
\text { enxerto }\end{array}$ & $\begin{array}{l}\text { \% de estacas } \\
\text { enraizadas }\end{array}$ & $\begin{array}{l}\% \text { de estacas } \\
\text { verdes }\end{array}$ & $\begin{array}{l}\% \text { de estacas } \\
\text { com calo }\end{array}$ & $\begin{array}{l}\% \text { de estacas } \\
\text { mortas }\end{array}$ \\
\hline 'Tsukuba-1' & $46,67 \mathrm{a}$ & $23,11 \mathrm{~b}$ & $12,44 \mathrm{a}$ & $17,78 \mathrm{~b}$ \\
\hline 'Tsukuba-2' & $20,00 \mathrm{~b}$ & $21,33 \mathrm{~b}$ & $19,11 \mathrm{a}$ & $39,56 \mathrm{a}$ \\
\hline 'Tsukuba-3' & $23,56 \mathrm{~b}$ & $12,89 \mathrm{~b}$ & $17,33 \mathrm{a}$ & $46,22 \mathrm{a}$ \\
\hline 'Okinawa' & $57,33 \mathrm{a}$ & $36,00 \mathrm{a}$ & $2,67 \mathrm{~b}$ & $4,00 \mathrm{c}$ \\
\hline $\mathrm{F}$ & $15,1235^{* *}$ & $10,614 * *$ & $9,5306^{* *}$ & $24,4971 * *$ \\
\hline \multicolumn{5}{|l|}{ AIB } \\
\hline $0 \mathrm{mg} \cdot \mathrm{L}^{-1}$ & $27,33 \mathrm{~b}$ & $31,00 \mathrm{a}$ & $17,33 \mathrm{a}$ & $24,33 \mathrm{a}$ \\
\hline $3.000 \mathrm{mg} \cdot \mathrm{L}^{-1}$ & $37,33 \mathrm{ab}$ & $23,33 \mathrm{ab}$ & $14,33 \mathrm{ab}$ & $25,00 \mathrm{a}$ \\
\hline $6.000 \mathrm{mg} \cdot \mathrm{L}^{-1}$ & $46,00 \mathrm{a}$ & $15,67 \mathrm{~b}$ & $7,00 \mathrm{~b}$ & $31,33 \mathrm{a}$ \\
\hline $\mathrm{F}$ & $5,1659 *$ & $9,4602 * *$ & $6,2437 * *$ & $1,0656^{\mathrm{ns}}$ \\
\hline $\mathrm{F}_{\text {nexAIB }}$ & $1,505^{\mathrm{ns}}$ & $1,9431^{\mathrm{ns}}$ & $1,5178^{\mathrm{ns}}$ & 1,6905 ns \\
\hline C.V. $(\%)$ & 24,68 & 21,10 & 34,00 & 30,02 \\
\hline
\end{tabular}

Médias seguidas por letras distintas, na mesma coluna, diferem entre si, pelo teste de Tukey. *significativo ao nível de 5\% de probabilidade; **significativo ao nível de $1 \%$ de probabilidade; ${ }^{\text {ns }}$ não significativo.

Fonte: Elaboração dos autores.

Segundo Gemma e Ushitani (1989), a época do ano apresenta efeito notável no enraizamento adventício de estacas herbáceas de porta-enxertos da Série 'Tsukuba'. Esses autores observaram que 'Tsukuba-1' apresentou enraizamento próximo a $45 \%$ em estacas coletadas no mês de julho (verão, no Japão), ou seja, similar ao do presente trabalho. No entanto, este mesmo porta-enxerto apresentou enraizamento inferior a $10 \%$, quando as estacas foram coletadas no mês de março (início da primavera, no Japão) e, no mês de outubro (outono, no Japão), o enraizamento de 'Tsukuba-1' foi de $100 \%$. Isso demonstra que os fatores externos e internos são variáveis ao longo do ano, os quais afetam a capacidade de formação de raízes adventícias.

Segundo Tworkoski, Miller e Scorza (2006), a taxa de auxina em toda a parte aérea, em pessegueiro, aumenta até 28 dias $(802 \mathrm{pmol} / \mathrm{g})$ após o início da brotação, diminuindo posteriormente e 
atingindo $261 \mathrm{pmol} / \mathrm{g}$, após 87 dias. Esta redução da quantidade de auxina endógena, no final do ciclo vegetativo, pode prejudicar o enraizamento, pois este fitoregulador tem a propriedade de promover o enraizamento adventício (BLYTHE et al., 2007). No Japão, Murai et al. (1999) verificaram que, em estacas herbáceas de umezeiro (Prunus mume Sieb. et Zucc.) tratadas com AIB, os percentuais de enraizamento decresceram de $50 \%$, no verão, para $0 \%$ de enraizamento, no outono. Segundo os autores, a época de coleta dos ramos influencia a formação de raízes adventícias, e o sucesso do enraizamento correlaciona-se positivamente com os conteúdos de sorbitol.

A porcentagem de calo em estacas de 'Okinawa', verificada no presente estudo, foi bastante baixa $(2,67 \%)$, similar ao verificado por Tofanelli, Ono e Rodrigues (2003). O tipo de estaca apical (com ou sem meristema) também apresenta influencia na ocorrência de calo (NACHTIGAL, 1999). De acordo com o autor, a variação na porcentagem de calo foi de 18,37 a $63 \%$, com estacas apicais com meristemas e apicais com folhas em três nós, respectivamente.

Entre os três porta-enxertos da série 'Tsukuba', não houve diferenças significativas nas porcentagens de estacas verdes e com calo (Tabela 1). Comparativamente ao 'Okinawa', verificase que os porta-enxertos 'Tsukuba' apresentaram maiores porcentagens de estacas com calo (que variou entre 12,44 e $19,11 \%$ ) e menores de estacas verdes (que variou entre 12,89 e $23,11 \%$ ). Diferenças entre cultivares de pessegueiro, quanto à formação de calo, também foram observadas em estacas herbáceas das cultivares Delicioso Precoce, Jóia-1 e Okinawa, as quais chegaram a 9,8\%, 15,1\% e 2,1\%, respectivamente (TOFANELLI; ONO; RODRIGUES, 2003).

$\mathrm{Na}$ prática, tem sido observado em estacas herbáceas de porta-enxertos de pessegueiro que, tanto as estacas com calo como as chamadas estacas verdes (que não enraizaram, não formaram calo e nem morreram) não formam raízes, mesmo que mantidas por períodos maiores do que 60 dias sob câmara de nebulização intermitente (MAYER; PEREIRA; NACHTIGAL, 2001), sugerindo que a formação de calo é inversamente proporcional à formação de raízes (NACHTIGAL, 1999). A formação de calo e de raízes são processos independentes para a maioria das plantas e a ocorrência simultânea é devido a condições internas e ambientais semelhantes (HARTMANN et al., 2002; CANLI; BOZKURT, 2009).

A mortalidade de estacas foi estatisticamente influenciada pelos porta-enxertos testados e considerada alta nos porta-enxertos 'Tsukuba-3' e 'Tsukuba-2' (46,22 e 39,56\%, respectivamente), intermediária em 'Tsukuba-1' (17,78\%) e desprezível em 'Okinawa' (4,0\%). Segundo Aguiar et al. (2005), a ausência de folhas em estacas semilenhosas de 'Okinawa', sob câmara de nebulização intermitente, aumenta a mortalidade de estacas, embora não influencie a porcentagem de enraizamento. As folhas e as gemas produzem auxinas e os carboidratos translocadosdas folhas sãoimportantesparaaformação e desenvolvimento das raízes (HARTMANN et al., 2002). Normalmente, em estacas herbáceas sob câmara de nebulização intermitente, a mortalidade de estacas é precedida pela queda das folhas originais da estaca. Diversos são os fatores que podem contribuir para a queda das folhas durante o período de enraizamento adventício, sendo, às vezes, difícil diagnosticar a causa principal. Dentre esses fatores, pode-se mencionar a má nutrição da planta matriz, o balanço hormonal endógeno favorável a senescência das folhas, problemas fitossanitários, o estresse hídrico e a inadequada regulagem dos períodos de acionamento e de desligamento do sistema de nebulização, o estresse térmico, bem como o uso de substratos ou recipientes inadequados. De Klerk, Krieken e De Jong (1999) citam a perda de água por transpiração e a baixa qualidade radicular entre as principais causas da morte em estacas herbáceas. No presente trabalho, é provável que o estresse térmico (declínio das temperaturas do ar durante o 
período de condução do experimento -Figura 1- e as diferenças entre temperaturas diurnas e noturnas), tenham favorecido a queda prematura das folhas e, consequentemente, provocado a morte das estacas.

$\mathrm{O}$ uso do ácido indolbutírico foi benéfico às estacas herbáceas dos porta-enxertos estudados, proporcionando aumento da porcentagem de enraizamento, a redução das porcentagens de estacas verdes e as com calo, e não influenciou a mortalidade (Tabela 1). Portanto, verifica-se que as doses de ácido indolbutírico testadas não foram fitotóxicas às cultivares estudadas e não foram responsáveis pela mortalidade das estacas. Ainda que não tenham sido detectadas diferenças significativas entre as doses 3.000 e $6.000 \mathrm{mg} . \mathrm{L}^{-1}$, nas variáveis apresentadas na Tabela 1, verifica-se a tendência de melhores resultados para a dose $6.000 \mathrm{mg} \cdot \mathrm{L}^{-1}$. Os benefícios do ácido indolbutírico na propagação vegetativa de porta-enxertos de pessegueiro, tais como aumento da taxa de enraizamento, do comprimento do sistema radicular e do número de raízes por estaca, tem sido relatada por diversos autores (NACHTIGAL, 1999; MAYER; PEREIRA; NACHTIGAL, 2001; TOFANELLI; ONO; RODRIGUES, 2003; SULUSOGLU; CAVUSOGLU, 2010).

Diferenças estatísticas entre os porta-enxertos também foram observadas na porcentagem de estacas inaptas ao transplantio, porcentagem de estacas aptas ao transplantio e no comprimento das raízes. Entretanto, não foram observadas diferenças entre os porta-enxertos no número de raízes por estaca (Tabela 2). As porcentagens de estacas aptas e inaptas ao transplantio são interdependentes, revelam a qualidade das raízes adventícias formadas e o rendimento ao transplantio. Ao observarmos essas duas variáveis conjuntamente, verifica-se a melhor qualidade de raízes no porta-enxerto 'Tsukuba-1' e a pior qualidade no porta-enxerto 'Tsukuba-2'. Os porta-enxertos 'Tsukuba-3' e 'Okinawa' apresentaram resultados intermediários, em ambas as variáveis. Analogicamente, 'Tsukuba-1' também foi um dos porta-enxertos que apresentou a maior porcentagem de enraizamento (Tabela 1), indicando características mais favoráveis desse porta-enxerto à propagação por estacas herbáceas, para a estaquia em março.

O comprimento médio das cinco maiores raízes foi estatisticamente influenciado pelos portaenxertos (Tabela 2). Os melhores resultados também foram observados em 'Tsukuba-1' $(8,14 \mathrm{~cm})$ e 'Tsukuba-3' (6,35 cm), que não diferiram entre si. Gemma e Ushitani(1989) não observaram diferenças no comprimento da raiz, em estacas herbáceas das cultivares 'Tsukuba 1', '2' e '3' coletadas no verão. Entretanto, no outono, 'Tsukuba-1' apresentou maior comprimento de raizes. Possivelmente esses efeitos qualitativos sejam devido às reservas endógenas nas estacas, um processo controlado diretamente ou indiretamente por genes (HARTMANN et al., 2002). No entanto, conforme observado no trabalho de Tsipouridis, Thomidis e Bladenopoulou (2006b), o conteúdo de reservas (açúcares, amido e sacarose) em porta-enxertos e cultivares-copa de pessegueiro é variável conforme a época do ano. A quantidade dessas reservas também influenciam o comprimento das raízes adventícias (AHMED; MOKHTAR, 2011). 
Figura 1. Temperaturas do ar $\left({ }^{\circ} \mathrm{C}\right)$ máximas e mínimas diárias, entre 15 de março e 15 de maio de 2010, registrados em uma estação meteorológica automática localizada no Posto Meteorológico da Sede da Embrapa Clima Temperado, Pelotas-RS.

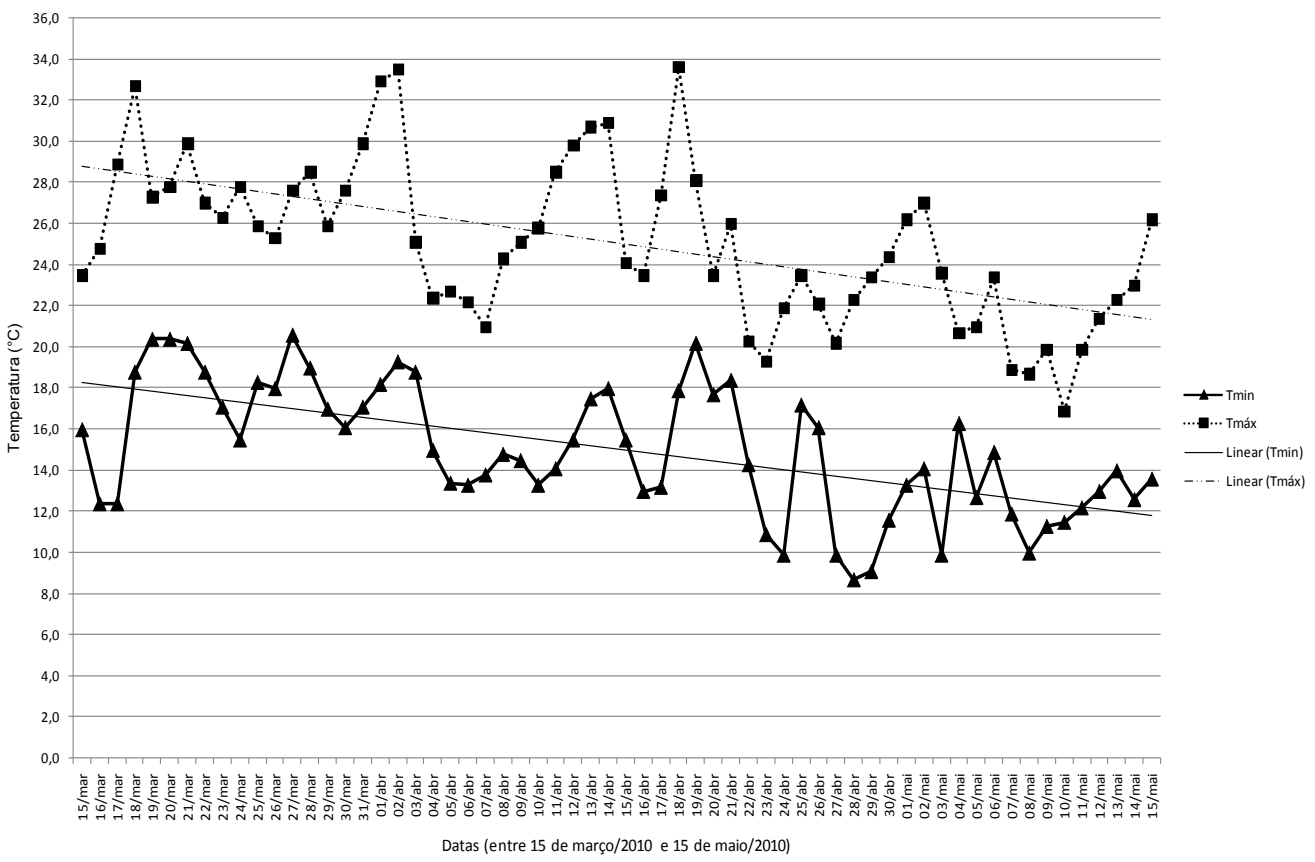

Fonte: CPACT (2012).

Tabela 2. Porcentagem de estacas inaptas e aptas ao transplantio, número de raizes por estaca e comprimento das cinco maiores raízes, em cultivares de porta-enxertos de pessegueiro tratadas com diferentes concentrações de ácido indolbutírico. Embrapa Clima Temperado, Pelotas-RS, maio de 2010.

\begin{tabular}{|c|c|c|c|c|}
\hline Porta-enxerto & $\begin{array}{l}\text { \% de estacas } \\
\text { inaptas }\end{array}$ & $\%$ de estacas aptas & $\begin{array}{l}\mathbf{N}^{0} \text { raízes/ } \\
\text { estaca }\end{array}$ & $\begin{array}{l}\text { Comprimento } \\
\text { de raízes }(\mathrm{cm})\end{array}$ \\
\hline 'Tsukuba-1' & $67,60 \mathrm{~b}$ & $32,40 \mathrm{a}$ & $2,42 \mathrm{a}$ & $8,14 \mathrm{a}$ \\
\hline 'Tsukuba-2' & $87,28 \mathrm{a}$ & $12,72 \mathrm{~b}$ & $1,81 \mathrm{a}$ & $4,63 \mathrm{~b}$ \\
\hline 'Tsukuba-3' & $83,19 \mathrm{ab}$ & $16,81 \mathrm{ab}$ & $1,82 \mathrm{a}$ & $6,35 \mathrm{ab}$ \\
\hline 'Okinawa' & $75,17 \mathrm{ab}$ & $24,83 \mathrm{ab}$ & $2,52 \mathrm{a}$ & $3,32 \mathrm{~b}$ \\
\hline $\mathrm{F}$ & $3,5889^{*}$ & $3,4887^{*}$ & $2,4062^{\mathrm{ns}}$ & $7,3960 * *$ \\
\hline \multicolumn{5}{|l|}{ AIB } \\
\hline $0 \mathrm{mg} \cdot \mathrm{L}^{-1}$ & 89,99 a & $10,01 \mathrm{~b}$ & $1,88 \mathrm{a}$ & $3,79 \mathrm{~b}$ \\
\hline $3.000 \mathrm{mg} \cdot \mathrm{L}^{-1}$ & 82,27 a & $17,35 \mathrm{~b}$ & $1,92 \mathrm{a}$ & $5,95 \mathrm{ab}$ \\
\hline $6.000 \mathrm{mg} \cdot \mathrm{L}^{-1}$ & $62,25 \mathrm{~b}$ & $37,75 \mathrm{a}$ & $2,64 \mathrm{a}$ & $7,20 \mathrm{a}$ \\
\hline $\mathrm{F}$ & $9,3518^{* *}$ & $9,5785^{* *}$ & $3,9562 *$ & $6,1784 * *$ \\
\hline $\mathrm{F}_{\text {pex } A \mathrm{IB}}$ & $0,8722^{\mathrm{ns}}$ & $0,8546^{\mathrm{ns}}$ & $0,5136^{\mathrm{ns}}$ & $1,9481 \mathrm{~ns}$ \\
\hline C.V. $(\%)$ & 20,90 & 50,95 & 35,13 & 41,23 \\
\hline
\end{tabular}

Médias seguidas por letras distintas, na mesma coluna, diferem entre si, pelo teste de Tukey. * significativo ao nível de $5 \%$ de probabilidade; ** significativo ao nível de $1 \%$ de probabilidade; ${ }^{\text {ns }}$ não significativo.

Fonte: Elaboração dos autores. 
O número médio de raízes adventícias por estaca não foi influenciado pelo porta-enxerto e foi considerado baixo (variou entre 1,81 a 2,52 raízes por estaca). Essa variável é também relacionada às elevadas porcentagens de estacas enraizadas inaptas ao transplantio (entre 67,60 e 87,28\%), cuja maioria apresentou uma ou duas raízes. Mayer, Pereira e Nachtigal (2001) também não observaram diferenças entre clones de umezeiro no número de raízes por estaca. Em porta-enxertos da Série 'Tsukuba' (1 ao 10), Gemma e Ushitani (1989) verificaram efeito dos porta-enxertos no número de raízes por estaca. Segundo Osterc, Stefancic e Stampar (2009), o número de raízes adventícias depende da característica fisiológica da estaca, sendo que quanto mais juvenil, maiores as possibilidades de haver incremento do número de raízes. É uma variável importante a ser avaliada na propagação por estaquia, pois está relacionada à capacidade de sobrevivência das estacas após a retirada do ambiente de enraizamento (NACHTIGAL, 1999).

As doses testadas de ácido indolbutírico influenciaram estatisticamente as porcentagens de estacas aptas e inaptas ao transplantio e o comprimento das raízes, entretanto não tiveram efeito no número de raízes por estaca (Tabela 2). Esses dados divergem do observado por Nachtigal (1999) que, em estacas herbáceas de 'Okinawa', verificou que o ácido indolbutírico promove acréscimo de mais de $400 \%$ no número de raízes. No presente trabalho, também verificou-se que a dose de $6.000 \mathrm{mg} . \mathrm{L}^{-1}$ apresentou os melhores resultados, pois reduziu a porcentagem de estacas inaptas ao transplantio $(62,25 \%)$, aumentou a porcentagem de estacas aptas ao transplantio $(37,75 \%)$ e o comprimento das raízes $(7,20 \mathrm{~cm})$.

A porcentagem de estacas aptas ao transplantio obtida no presente trabalho $(37,75 \%)$, com o uso de $6.000 \mathrm{mg} . \mathrm{L}^{-1}$ de ácido indolbutírico, pode ser considerada satisfatória, principalmente quando se leva em consideração a época do ano em que a estaquia foi realizada, considerada como marginal para a estaquia herbácea no Sul do Brasil, além da ausência de controles de temperatura do ar e do leito de enraizamento, na câmara de nebulização utilizada.

A temperatura do ar ao redor das plantas matrizes durante o crescimento dos ramos, bem como a temperatura do substrato de enraizamento, exercem influência na formação de raízes adventícias (HARTMANN et al., 2002). Segundo os autores, para a maioria das espécies de clima temperado, a temperatura ótima do substrato de enraizamento situa-se entre 18 e $25^{\circ} \mathrm{C}$. Temperaturas do ar diurnas, entre 21 e $27^{\circ} \mathrm{C}$, e noturnas, ao redor de $15^{\circ} \mathrm{C}$, são satisfatórias, durante o período de enraizamento. Não foram registradas as temperaturas no interior da estufa agrícola, durante o período de condução do experimento. Entretanto, segundo Reisser Júnior (2002), as temperaturas do ar no interior de uma estufa agrícola tipo túnel, com cobertura de polietileno e telas anti-insetos nas laterais (idêntica ao ambiente utilizado no presente trabalho), apresentam estreita relação com às temperaturas do ar no ambiente externo, não havendo diferenças de mais de $1^{\circ} \mathrm{C}$ nas temperaturas do ar mínimas ou em torno de $2,5^{\circ} \mathrm{C}$ nas temperaturas do ar máximas, entre os dois ambientes.

A Figura 1 apresenta os dados de temperatura do ar máxima e mínima diária, durante o período de condução do experimento, obtidas em estação meteorológica automática (CPACT, 2012) localizada próxima à estufa agrícola onde o experimento foi conduzido. No período considerado (15 de março a 15 de maio de 2010), observa-se que houve decréscimos lineares e contínuos das temperaturas máximas e mínimas diárias. A menor temperatura mínima, a maior temperatura máxima e a maior amplitude térmica diária, registradas no período, foram de $8,7^{\circ} \mathrm{C}, 33,6^{\circ} \mathrm{C}$ e $16,5^{\circ} \mathrm{C}$, respectivamente. Também observou-se que, durante o período de 60 dias de condução do experimento, ocorreram 31 dias com temperaturas do ar mínimas $<15^{\circ} \mathrm{C}$ e 20 dias com temperaturas do ar máximas $>27^{\circ} \mathrm{C}$. Desta forma, possivelmente as temperaturas mínimas e máximas, registradas no período de condução 
do experimento, tenham impedido a obtenção de maiores percentuais de enraizamento, no presente experimento, uma vez que a câmara de nebulização utilizada não possui controles de temperatura do ar ou do leito de enraizamento.

Os resultados revelaram que a propagação por estacas herbáceas no final do ciclo vegetativo (março), com o uso do último fluxo de crescimento, pode ser tecnicamente viável para alguns portaenxertos de pessegueiro, ainda que normalmente ocorram temperaturas mínimas e máximas desfavoráveis ao enraizamento, na região de Pelotas-RS. A estaquia herbácea realizada em março pode aumentar a capacidade de produção da infra-estrutura necessária (câmaras de nebulização intermitente e de aclimatação), tornando-se uma tecnologia de mais fácil adoção por parte dos viveiristas.

\section{Conclusões}

Nas condições experimentais adotadas, é possível concluir que:

1- O uso de ramos herbáceos, oriundos do último fluxo de crescimento, para a estaquia em março, proporciona resultados satisfatórios para a propagação dos porta-enxertos 'Okinawa' e 'Tsukuba 1'.

2- Os três porta-enxertos da série 'Tsukuba' testados apresentam diferenças na porcentagem de enraizamento, nas porcentagens de estacas aptas e inaptas ao transplantio, no comprimento das raízes adventícias formadas e na porcentagem de mortalidade.

3- O ácido indolbutírico, na dose de 6.000 mg. $\mathrm{L}^{-1}$, pode ser recomendado para o tratamento de estacas herbáceas dos porta-enxertos testados, para estaquia em março.

\section{Agradecimentos}

À Embrapa, à Capes e ao $\mathrm{CNPq}$, pelo apoio financeiro.

\section{Referências}

AGUIAR, R. S. de; SANTOS, C. E. dos; ZIETEMANN, C.; ASSIS, A. M. de; MORAIS, V. J. de; ROBERTO, S. R. Enraizamento de estacas semilenhosas do pessegueiro 'Okinawa' submetidas a diferentes dosagens de ácido indolbutírico. Acta Scientiarum, Maringá, v. 27, n. 3, p. 461-466, 2005.

AHMED, M. K. A. E.; MOKHTAR, M. S. Why some grapevine cultivars are hard to root? Australian Journal of Basic and Applied Sciences, Amman, v. 5, n. 2, p. 110116, 2011.

ANCU, S.; DUTU, I.; INDREAS, A.; IANCU, M.; ANCU, I. Vegetative rootstocks recently registered and promising selections of the stone fruit species. Bulletin UASVM Horticulture, Romênia, v. 66, n. 1, p. 103-110, 2009.

BLYTHE, E. K; SIBLEY, J. L.; TILT, K. M.; RUTER, J. M. Methods of auxin application in cutting propagation: A review of 70 years of scientific discovery and commercial practice. Journal of Environmental Horticulture, Washington, v. 25, n. 3, p. 166-185, 2007.

BRASIL. Instrução normativa n. 24, de 16 de dezembro de 2005. Normas para produção, comercialização e utilização de mudas. Diário Oficial [da] República Federativa do Brasil, Poder Executivo, Brasília, DF, 20 dez. 2005. Seção 1, p. 5-27.

CANLI, F. A.; BOZKURT, S. Effects of indolebutyric acid on adventitious root formation from semi-hardwood cuttings of 'Sarierik' plum. Journal of Applied Biological Sciences, Islamabad, v. 3, n. 1, p. 40-43, 2009.

CARDOSO, C.; YAMAMOTO, L. Y.; PRETI, E. A.; ASSIS, A. M. de; NEVES, C. S. V. J.; ROBERTO, S. R. AIB e substratos no enraizamento de estacas de pessegueiro 'Okinawa' coletadas no outono. Semina: Ciências Agrárias, Londrina, v. 32, n. 4, p. 1307-1314, 2011.

COMISSÃO ESTADUAL DE SEMENTES E MUDAS. Normas e padrões de produção de mudas de fruteiras para o Estado do Rio Grande do Sul. Porto Alegre: CESM, 1998. $100 \mathrm{p}$.

CPACT - Laboratório de Agrometeorologia. Disponível em: <http://www.cpact.embrapa.br/agromet/>. Acesso em: 02 out. 2012.

DE KLERK, G. J.; KRIEKEN, W. V. D.; DE JONG, J. C. Review the formation of adventitious roots: New concepts, new possibilities. In Vitro Cellular \& Developmental Biology - Plant, Wageningen, v. 35, n. 3, p. 189-199, 1999.

DE ROSSI, A.; FACHINELLO, J. C.; RUFATO, L.; PARISOTTO, E.; PICOLOTTO, L.; KRUGER, L. R. Comportamento do pessegueiro 'Granada' sobre 
diferentes porta-enxertos. Revista Brasileira de Fruticultura, Jaboticabal, v. 26, n. 3, p. 446-449, 2004.

GEMMA, H.; USHITANI, A. Rooting of cuttings in the peach rootstocks: Tsukuba $\mathrm{n}^{\mathrm{o}} 1 \sim 10$. Journal of the Japanese Society for Horticultural Science, Tokyo, v. 58, separata 1, p. 94-95, 1989.

HARTMANN, H. T.; KESTER, D. E.; DAVIES JUNIOR, F. T.; GENEVE, R. L. Plant propagation: principles and practices. 7. ed. New Jersey: Prentice Hall, 2002. 880 p.

MAYER, N. A.; ANTUNES, L. E. C. Diagnóstico do sistema de produção de mudas de Prunóideas no Sul e Sudeste do Brasil. Pelotas, Embrapa Clima Temperado, 2010. 53 p. (Documentos, 293).

MAYER, N. A.; PEREIRA, F. M.; NACHTIGAL, J. C. Propagação do umezeiro (Prunus mume Sieb \& Zucc.) por estaquia herbácea. Revista Brasileira de Fruticultura, Jaboticabal, v. 23, n. 3, p. 673-676, 2001.

MILlER, P. J.; PARFITT, D. E.; WEINBAUM, S. A. Outcrossing in peach. HortScience, Alexandria, v. 24, n. 2, p. 359-360, 1989.

MINDÊLLO NETO, U.; BALBINOT JÚNIOR, A. A.; HIRANO, E. Efeito do ácido indolbutírico no enraizamento de estacas herbáceas de dois porta-enxertos de pessegueiro. Revista Brasileira de Agrociência, Pelotas, v. 10, n. 4, p. 433-437, 2004.

MURAI, Y.; HARADA, H.; MOCHIOKA, R.; OGATA, T.; SHIOZAKI, S.; HORIUCHI, S.; MUKAI, H.; TAKAGI, T. Relationships between rooting in softwood cuttings of mume (Prunus mume Sieb. et Zucc.) and sorbitol in shoots. Journal Japanese Society of Horticultural Science, Tokyo, v. 68, n. 3, p. 648-654, 1999.

NACHTIGAL, J. C. Obtenção de porta-enxertos 'Okinawa'e de mudas de pessegueiro (Prunus persica (L.) Batsch) utilizando métodos de propagação vegetativa. 1999. Tese (Doutorado em Agronomia) - Faculdade de Ciências Agrárias e Veterinárias. Universidade Estadual Paulista, Jaboticabal.

OSTERC, G.; STEFANCIC, M.; STAMPAR, F. Juvenile stockplant material enhances root development through higher endogenous auxin level. Acta Physiologica Plantarum, Warszowa, v. 31, n. 5, p. 899-903, 2009.

PEREIRA, F. M.; MAYER, N. A. Pessegueiro: tecnologias para a produção de mudas. Jaboticabal: Funep, 2005. 65 p.

REISSER JÚNIOR, C. Alterações físicas em ambientes de estufa plástica e seus efeitos sobre as condições hídricas e o crescimento do tomateiro. 2002. Tese (Doutorado em Agrometeorologia) - Faculdade de
Agronomia. Universidade Federal do Rio Grande do Sul, Porto Alegre.

ROCHA, M. da S.; BIANCHI, V. J.; FACHINELLO, J. C.; SCHMITZ, J. D.; PASA, M. da S.; SILVA, J. B. da. Comportamento agronômico inicial da cv. Chimarrita enxertada em cinco porta-enxertos de pessegueiro. Revista Brasileira de Fruticultura, Jaboticabal, v. 29, n. 3, p. 583-588, 2007.

SHARPE, R. H. Okinawa peach shows promising resistance to root-knot nematodes. Proceedings of the Florida State for Horticultural Society, Tallahassee, v. 70, p. 320-322, 1957.

SUlusoGLU, M.; CAVUSOGLU, A. Vegetative propagation of cherry laurel (Prunus laurocerasus L.) using semi-hardwood cuttings. African Journal of Agricultural Research, Ekapoma, v. 5, n. 23, p. 31963202, 2010.

TOFANELLI, M. B. D.; ONO, E. O.; RODRIGUES, J. D. Método de aplicação de ácido indolbutírico no enraizamento de estacas herbáceas de pessegueiro. Revista Brasileira de Fruticultura, Jaboticabal, v. 25, n. 2, p. 363-364, 2003.

TSIPOURIDIS, C.; THOMIDIS, T.; MICHAILIDES, $Z$. Influence of some external factors on the rooting of GF677, peach and nectarine shoot hardwood cuttings. Australian Journal of Experimental Agriculture, Collingwood, v. 45, n. 1, p. 107-113, 2005.

TSIPOURIDIS, $\quad$ C.; $\quad$ THOMIDIS, $\quad$ T.; BLADENOPOULOU, S. Seasonal variation in sprouting of GF677 peach x almond (Prunus persica x Prunus amygdalus) hybrid root cuttings. New Zealand Journal of Crop and Horticultural Science, Wellington, v. 34, n. 1, p. 45-50, 2006a.

Rhizogenesis of GF677, early crest, may crest and arm king stem cuttings during the year in relation to carbohydrate and natural hormone content. Scientia Horticulturae, Amsterdam, v. 108, n. 2, p. 200-204, 2006b.

TWORKOSKI, T.; MILLER, S.; SCORZA, R. Relationship of pruning and growth morphology with hormone ratios in shoots of pillar and standard peach trees. Journal of Plant Growth Regulation, New York, v. 25, n. 2, p. 145-155, 2006.

TWORKOSKI, T.; TAKEDA, F. Rooting response of shoot cuttings from three peach growth habits. Scientia Horticulturae, Amsterdam, v. 115, n. 1, p. 98-100, 2007.

YOSHIDA, M. Pessegueiro. In: KAWASE, K. (Ed.). Uso e características de porta-enxerto de fruteiras. Tóquio: Nobunkyo, 1995. p. 339-372. 
